\title{
Isolated right superior vena cava draining into the left atrium in a child with vein of Galen aneurysmal malformation-case report
}

\author{
Ahmed F. Elmahrouk ${ }^{1,3^{*}+}$ (D), Abdelmonem Helal ${ }^{2,4+}$, Mohamed F. Ismail ${ }^{1,5}$, Tamer Hamouda ${ }^{1,6}$, \\ Mohammed Mashali, ${ }^{2,4}$, Ahmed A. Jamjoom ${ }^{1}$ and Jameel A. Al-Ata ${ }^{2,7}$
}

\begin{abstract}
Background: Isolated right Superior Vena Cava drainage into the left atrium in the absence of other cardiac anomalies is an extremely rare condition. The vein of Galen aneurysmal malformation is a congenital vascular malformation. It comprises $1 \%$ of all pediatric congenital anomalies. The association vein of Galen aneurysmal malformation, with congenital heart disease has been described.

Case presentation: We describe a 16-months old toddler presenting at 7-months of age with respiratory distress and cyanosis. CT brain showed Vein of Galen aneurysmal malformations. Echocardiography showed partial anomalous systemic venous drainage in the form of right superior vena cava drained into left atrium. Four sessions of Endovascular embolization were performed. Surgical repair of partial anomalous systemic venous drainage was done successfully.

Conclusions: The superior vena cava in our case overrides the atrial septum promoting direct drainage of venous return into the $L A$, thus causing dilated left ventricle instead of dilatation of right ventricle which is the usual presentation of VAGMs.
\end{abstract}

Keywords: Vein of Galen aneurysmal malformations, Partial anomalous systemic venous drainage, Endovascular embolization

\section{Background}

Isolated right Superior Vena Cava (RSVC) drainage into the left atrium (LA) in the absence of other cardiac anomalies is an extremely rare condition. It accounts for approximately $0.5 \%$ of congenital cardiac cases [1]. The vein of Galen aneurysmal malformation (VGAM) is a congenital vascular malformation. It manifests in the first year of birth with high output cardiac failure, and comprises $30 \%$ of the pediatric vascular and $1 \%$ of all pediatric congenital anomalies [2].

\footnotetext{
* Correspondence: a_marouky@hotmail.com; ael-mahrouk@kfshrc.edu.sa; Ahmed.elmahrouki1@med.tanta.edu.eg

${ }^{+}$Ahmed F. ElMahrouk and Abdelmonem Helal contributed equally to this work.

${ }^{1}$ Cardiothoracic Surgery Department, King Faisal Specialist Hospital and Research Center, Jeddah, Saudi Arabia

${ }^{3}$ Cardiothoracic Surgery Department, Faculty of Medicine, Tanta University, Tanta, Egypt

Full list of author information is available at the end of the article
}

\section{Case presentation}

A sixteen-months toddler, initially diagnosed at the age of 7 months, to have VGAM and anomalous systemic venous drainage of the RSVC to LA. He first came to the emergency department with respiratory distress, mild cyanosis and moderate hydrocephalus.

On arrival to the emergency room, he was alert, active, afebrile and hemodynamically stable. His oxygen saturation was $80 \%$ and head circumference was $45 \mathrm{~cm}$. Chest-X-ray showed cardiomegaly and echocardiography revealed a dilated RSVC draining into the LA with a patent foramen oval shunting left to right. The pulmonary veins were well seen and were normally draining to the LA, whereas the inferior vena cava and the hepatic veins drain into the right atrium (RA). The LA and left ventricle were both mildly dilated (Fig. 1a). 


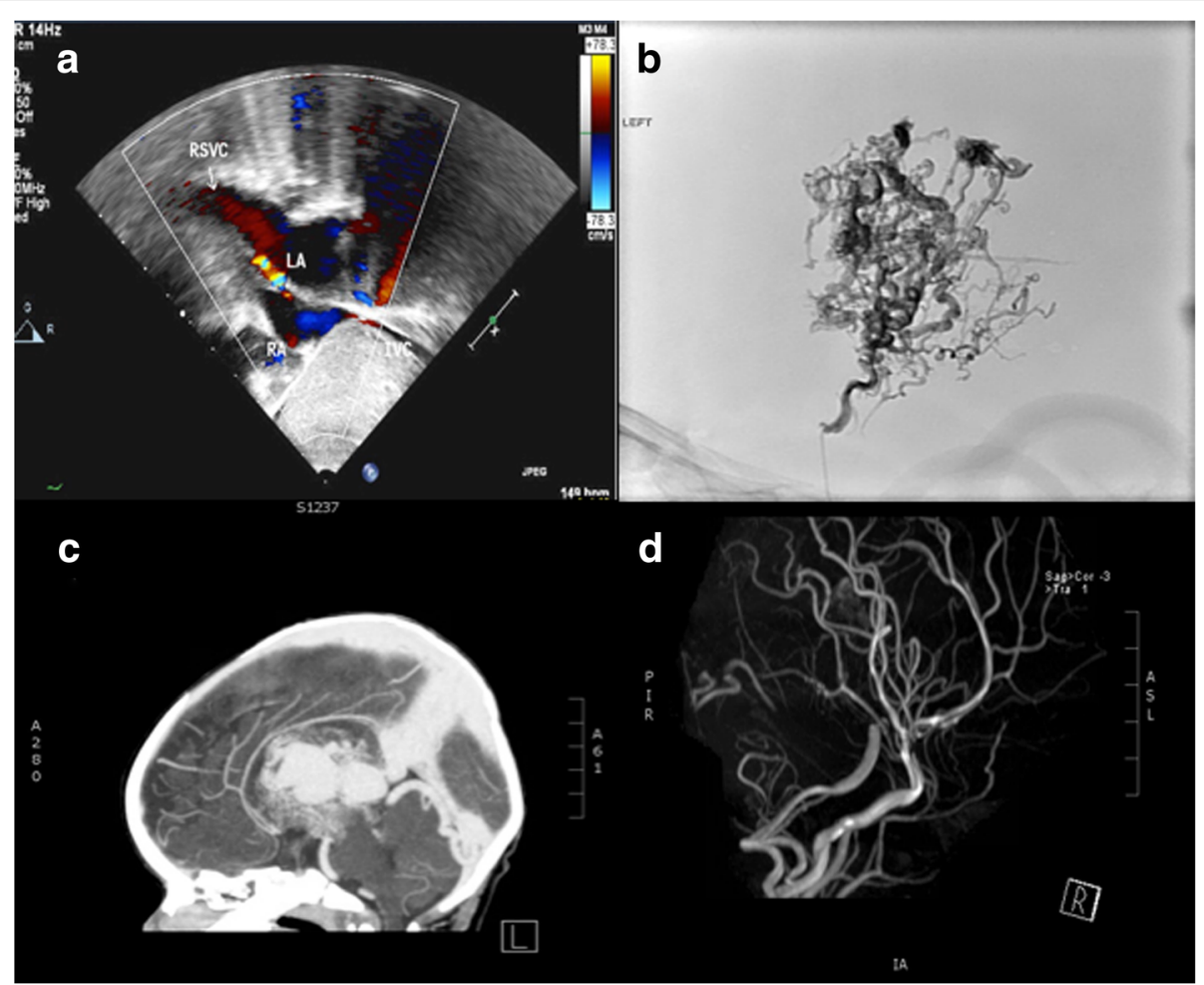

Fig. 1 a Echocardiography modified bicaval view showing dilated right superior vena cava (RSVC) draining into dilated the dilated left atrium (LA). Inferior vena cava (IVC) is draining normally to the right atrium (RA). b Selective Angiography with multiple supplying vessels of a large arteriovenous malformation deeply located in the left basal ganglia with drainage into MProsV of Markowski that drains into the vein of Galen. c Moderate hydrocephalus is present. The maximum size of the arteriovenous malformation is approximately $4.9 \mathrm{~cm}$ in size. The Arterial supply from middle cerebral artery and anterior cerebral artery small branches. The venous drainage through MProsV of Markowski that drains into the vein of Galen with significant dilatation of the torcula and the transverse sinuses. $\mathbf{d}$ MR angiography and MR venogram: Complete obliteration of the arteriovenous malformation and the arteriovenous shunting. No further embolization is needed

A trans-fontanelle ultrasound showed dilated lateral ventricles and third ventricle with evidence of flow seen by color Doppler. Further evaluation by CT brain angiogram showed a large intraventricular hematoma in the left lateral ventricle, a $4.9 \mathrm{~cm}$ arteriovenous malformation with markedly distended venous arteries involving the basal ganglia extending to the left lateral ventricle (Fig. 1b).

The arterial supply was predominantly from middle cerebral artery and anterior cerebral artery small branches. The venous drainage was through the median prosencephalic vein (MProsV) of Markowski into the vein of Galen (Fig. 1c).

Four sessions of stepwise embolization of the VGAM was performed, with 2 months interval, however, he developed an intraventricular hemorrhage with progressive hydrocephalus and acute infarction in the left superior fronto-parietal region. Ventriculo-peritoneal shunt was inserted to decrease the intracranial pressure. After 4 months of follow up with pediatric neurology patient examination showed motor developmental delay in the form of delayed sitting without support and minimal right hemiparesis. Follow-up MRI brain showed evidence for left-sided subdural hygroma with associated minimal shift of the midline towards the right side and complete obliteration of the arteriovenous malformation and the arteriovenous shunting (Fig. 1d) The patient was cleared for cardiac procedure.

At the age of 16 months, the patient underwent surgical re-routing of the RSVC to the RA through median sternotomy using cardiopulmonary bypass. Intraoperative examination revealed posterior displacement of the RSVC which drain into the LA, there was no Left SVC (Fig. 2a) Just before the RSVC-LA connection a small separate channel was identified (Fig. 2b) The right atrial appendage was opened; this channel was found to drain into RA and no sinus venousus (SV) defect was found. The inferior vena cava and pulmonary veins drained normally. The RSVC was amputated $2 \mathrm{~cm}$ proximal to the RSVC-LA junction, the distal end of the RSVC was over-sewn and the proximal end was connected to the opening in the right atrial appendage (Fig. 3).

He was seen in the outpatient clinic with a remarkable improvement in cognitive and motor function with oxygen saturation above $97 \%$. 


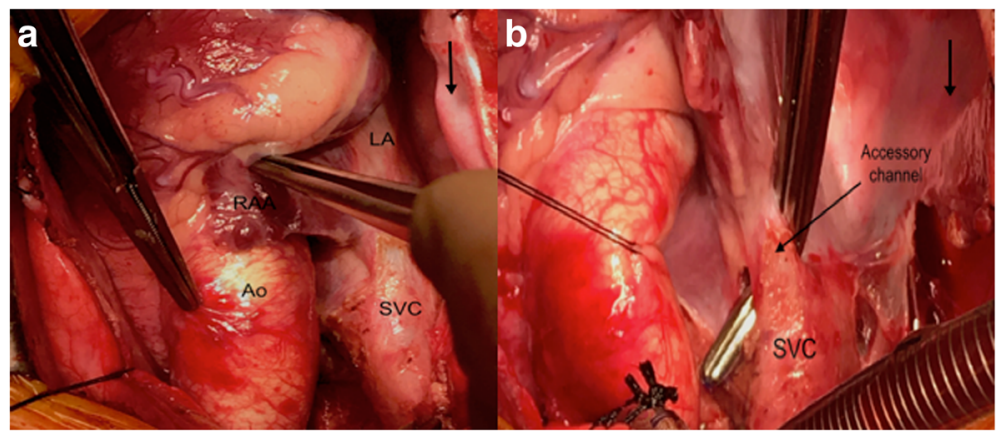

Fig. 2 a Intra-operative view with Superior Vena Cava (SVC) draining into the Left Atrium (LA), The Aorta (Ao) is pulled with the left forceps and the Right Atrial appendage (RAA) is pulled with the right forceps. An arrow on the right angle (surgeon side) pointing toward the head of the patient. b Intra-operative view showing the right-angle forceps separating a small accessory channel originating from the SVC, the channel drains to the right atrium while the main SVC is draining to the left Atrium. An arrow on the right angle (surgeon side) pointing toward the head of the patient

\section{Discussion}

The high-flow, low-resistance arteriovenous connection in VGAM causes a compensatory increase in blood volume and cardiac output and lead to High output cardiac failure [2]. in our case the presentation was different due to RSVC-LA, that leads to hemodynamic modification in the form of central cyanosis and increased left ventricular end diastolic pressure, and pulmonary venous congestion. It is important to recognize the potential importance of right-left shunt (RSVC-LA), which leads to a high volume of systemic venous return. Any connection between the venous and arterial systems poses a

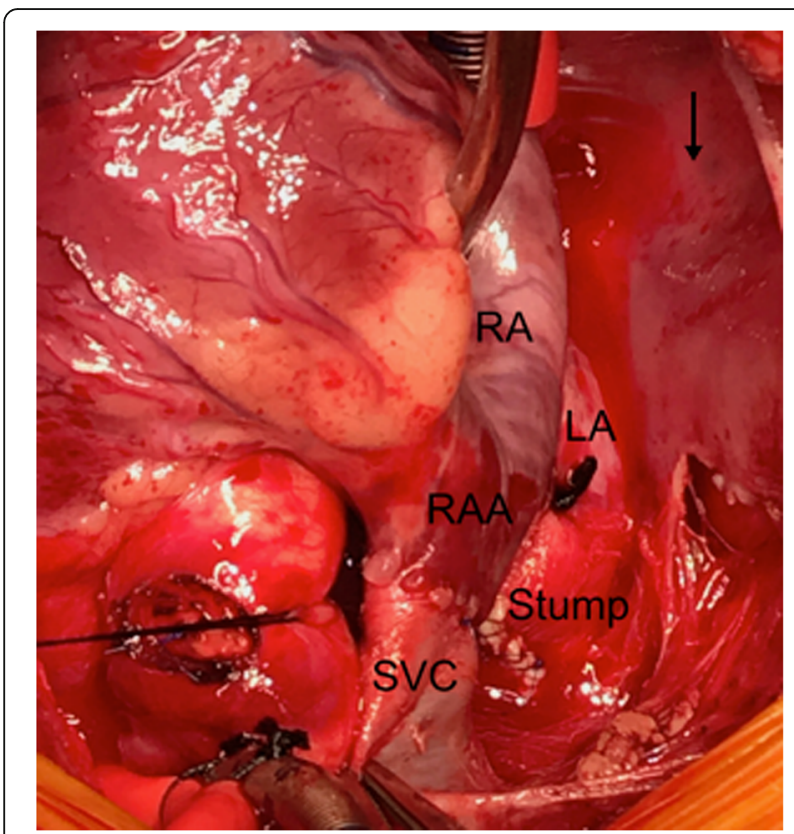

Fig. 3 Intra-operative view showing the proximal SVC anastomosis with the RAA, and the distal SVC stump is over-sewn and the small channel is ligated. An arrow on the right angle (surgeon side) pointing toward the head of the patient substantial risk of brain abscess and paradoxical embolization $[2,3]$.

The VGAM is the dominant lesion in neonates with associated congenital heart disease, its repair or palliation should take priority over correction of the cardiac defects. Endovascular intervention is the first-line of management $[2,3]$. .Ideally, the treatment should start at 4-5 months of age to maximize efficacy of the intervention and minimize the risk of delay in cerebral maturation. Our patient was presented at the age of 7 months. A stepwise endovascular embolization is recommended to avoid rapid hemodynamic changes, which can lead to parenchymal hemorrhage or massive venous thrombosis [2].

The association between isolated RSVC drainage of into LA and VGAMs, can be explained by the increased venous return through the SVC in utero that could interfere with the absorption of the right horn of the SV. This may lead to a relative leftward and cephalic distortion of the right horn of the SV, this results in opening of the SVC into the LA $[4,5]$.

\section{Conclusion}

In conclusion, the SVC in our case overrides the atrial septum promoting direct drainage of venous return into the LA, thus causing dilated left ventricle instead of dilatation of right ventricle which is the usual presentation of VAGMs.

\section{Abbreviations \\ (MProsV) of Markowski: The median prosencephalic vein; LA: Left Atrium; RA: The Right Atrium; RSVC: Right Superior Vena Cava; SV: Sinus Venousus;} VGAM: The vein of Galen aneurysmal malformation

\section{Funding}

This research received no specific grant from any funding agency in the public, commercial, or not-for-profit sectors.

Availability of data and materials

Data are available on request to the corresponding author. 


\section{Authors' contributions}

AE was involved in the analysis and interpretation of data, and drafted the manuscript "corresponding author", AH was involved in the analysis and interpretation of data and drafted the manuscript, $\mathrm{Ml}$ conducted the literature search, TH Data Collection, MM conducted the literature search, AJ conducted the review of data And JA-A conducted the final review. All authors read and approved the final manuscript.

\section{Ethics approval and consent to participate}

The report was approved by the Institutional Review Board Committee of King Faisal Specialist hospital and research center Jeddah, Saudi Arabia.

\section{Consent for publication}

Was obtained from the patient's legal guardian.

\section{Competing interests}

The authors declare that they have no competing interests.

\section{Publisher's Note}

Springer Nature remains neutral with regard to jurisdictional claims in published maps and institutional affiliations.

\section{Author details}

${ }^{1}$ Cardiothoracic Surgery Department, King Faisal Specialist Hospital and Research Center, Jeddah, Saudi Arabia. ${ }^{2}$ Department of Pediatric Cardiology, King Faisal Specialist Hospital and Research Center, Jeddah, Saudi Arabia. ${ }^{3}$ Cardiothoracic Surgery Department, Faculty of Medicine, Tanta University, Tanta, Egypt. ${ }^{4}$ Department of Pediatric Cardiology, Qasr Alainy Faculty of Medicine, Cairo University, Cairo, Egypt. ${ }^{5}$ Cardiothoracic Surgery Department, Faculty of Medicine, Mansoura University, Manasoura, Egypt. ${ }^{6}$ Cardiothoracic Surgery Department, Faculty of Medicine, Benha University, Benha, Egypt. ${ }^{7}$ Department Of Pediatrics, Faculty of Medicine, King Abdulaziz University, Jeddah, Saudi Arabia.

Received: 15 March 2018 Accepted: 1 June 2018

Published online: 13 June 2018

\section{References}

1. Baggett C, Skeen SJ, Gantt DS, Trotter BR, Birkemeier KL. Isolated right superior vena cava drainage into the left atrium diagnosed noninvasively in the Peripartum period. Tex Heart Inst J. 2009;36:611-4.

2. Recinos PF, Rahmathulla G, Pearl M, Recinos VR, Jallo Gl, et al. Vein of Galen malformations: epidemiology, clinical presentations, management. Neurosurg Clin N Am. 2012;23(1):165-77.

3. McElhinney DB, Halbach W, Silverman NH, Dowd CF, Hanley FL. Congenital cardiac anomalies with vein of Galen malformations in infants. Arch Dis Child. 1998;78(6):548-51.

4. Kirsch WM, Carlsson E, Hartmann AF Jr. A case of anomalous drainage of the superior vena cava into the left atrium. J Thorac Cardiovasc Surg. 1961 41:550-6.

5. Van Praagh S, Geva T, Lock JE, del Nido PJ, Vance MS, Van Praagh R. Biatrial or left atrial drainage of the right superior vena cava: anatomic morphogenetic, and surgical considerations: report of three new cases and literature review. Pediatr Cardiol. 24:350-63.

\section{Ready to submit your research? Choose BMC and benefit from:}

- fast, convenient online submission

- thorough peer review by experienced researchers in your field

- rapid publication on acceptance

- support for research data, including large and complex data types

- gold Open Access which fosters wider collaboration and increased citations

- maximum visibility for your research: over $100 \mathrm{M}$ website views per year

At BMC, research is always in progress.

Learn more biomedcentral.com/submissions 